\title{
Spiritual, Religious and Ethical Values in a Suicidal Individual
}

\author{
Ana Cristina Lopes and Diogo Telles Correia
}

\subsection{Introduction}

In a multi-faith and multicultural world, psychiatrists and other mental health professionals are confronted by distressed patients for whom religious beliefs shape psychopathological symptoms and their compliance with treatment. Therefore, religious and spiritual factors should be debated in the context of the patient's psychiatric diagnosis and also taken into account in the process of choosing the appropriate psychiatric treatment.

We present a clinical vignette of a 62-year-old sacristan who was admitted to the Psychiatric Emergency Room for suicidal thoughts in the context of physical sequelae of a cardiac episode. He confessed that, in the process of coping with his illness, he had a distressing experience of guilt and of losing his religious faith and shared the intention to take his own life by hanging himself.

In the discussion that follows we reflect upon the association between spiritual values, religiosity and suicidal ideation, by exploring whether some experiences should be classified as symptoms of a psychiatric disorder or crises within spiritual life. As will be seen cultural values play a key role in this. Themes that emerge include issues related to the boundaries of psychiatric diagnosis, the spiritual dimension of mental health and the values that underlie clinical decision-making regarding a suicidal individual.

\footnotetext{
A. C. Lopes ( $\square)$

Departamento de Psiquiatria, Centro Hospitalar de Entre o Douro e Vouga, Santa Maria da Feira, Portugal

e-mail: ana.lopes@chedv.min-saude.pt

D. T. Correia

Clinica Universitária de Psiquiatria e Psicologia, Faculdade de Medicina da Universidade de Lisboa, Lisbon, Portugal 


\subsection{Narrative Vignette}

We present a case of a 62-year-old man who was referred to the Psychiatric Emergency Room by his general practitioner, reporting suicidal thoughts during a routine appointment.

M.S grew up in a traditional family and was living with his wife and daughter in a rural area of the north of Portugal. He used to be socially and political engaged, as well as a practicing catholic, having been appointed to take charge of the church daily care as a sacristan.

In the Psychiatry Emergency Service he was calm and collaborative, talking openly about his health problems. He said that he had suffered from two heart attacks, 2 years ago, and had developed dyspnea on moderate effort and erectile dysfunction, secondary to cardiovascular disease.

To cope with these sequelae, he had been seeking care from multiple cardiologists, with no satisfactory outcome. He came across as very rational, focusing on his somatic complaints and his impaired sexual function, which he could no longer accept.

He found it difficult to express his innermost feelings, but in the course of the interview he described how persistent physical limitation had been humiliating when facing his wife and friends. Believing that he could no longer "play the role of the man of the family", which had come up in recent arguments with his wife, he admitted his intention to take his own life, by hanging himself, once he had taken legal measures relating to his inheritance. "I'm not afraid to die... If I can no longer work... I have no reasons to hang on ... I can't even pick up weights... all I want is to provide a future for my daughter", he claimed. He said he had shared his suicidal thoughts with two friends that told him "to be calm".

Considering his role as a sacristan, we explored his religious commitment and participation, and whether he had used his spirituality to help cope with his illness. In that moment, he tried to avoid the question, claiming that he had continued to be actively involved in all the church activities, but when encouraged to open up and talk about the things he really needed to express, he became more comfortable with sharing his feelings.

He revealed that he had lost his faith and showed signs of spiritual distress. He also shared the belief that his disease was some kind of punishment, since he used to be sexually active and had had an extramarital affair. Such behaviour made him experience feelings of guilt and worthlessness and he confessed that erectile dysfunction had led to reduced self esteem and low confidence.

During the psychopathological assessment he reported no other symptoms compatible with depressive disorder such as depressed mood, loss of interest and pleasure in hanging out with friends, diminished ability to think or concentrate, and loss of appetite. Furthermore, he still looked hopeful, since he carried on making appointments with several cardiologists in order to find a treatment for his medical condition. 


\subsection{Discussion}

Although M.S. revealed some depressive symptoms, his clinical picture is "subthreshold", that is he does not meet the full clinical criteria for a major depressive episode. Besides, the severity of some of his symptoms (like his feelings of guilt) reflects his use of religion to understand and deal with his disease.

Individuals struggle to make sense of their experiences in the light of their beliefs and religious vocation. How a person copes with an illness, therefore, depends on their beliefs and assumptions about himself or herself and their disease, about their life and what it should look like, their sense of competence and control. Serious illness challenges many assumptions, and the attribution of meaning to the experience of suffering is the crucial element acting as a cathartic agent.

In the case of this man, a practicing catholic and sacristan, an internal struggle is evident, in the conflict between his declared values and his actions, resulting in guilt, anxiety and low self-esteem. In the interview, he also talked about his loss of faith, which reflected his struggle with God, and how this was related to a feeling of loss of contact with this reality and a sense of rejection. It was these that had led to the profound loss he felt in the meaning of his life (an experience shared by many others) and that drove his desperate suicidal intention (contrary to the generally accepted observation that religious commitment may protect against suicide [1]).

\subsection{Religion, Values and Mental Health Issues}

There are contrasting ways of understanding the influence of M.'s religion on his current problems. On the one hand, the act of adultery within his faith is very distressing because it is considered a mortal sin forbidden by God and it is against one of the Ten Commandments.

From this point of view, it is understandable that M. experienced his disease not only as a loss of dignity or integrity, but also as a punishment for his sin, to the extent that this is congruent with the belief system of the cultural and religious group to which he belongs.

This belief could have a negative effect on mental health, causing feelings of guilt, rumination and angst, and often becoming intricately entangled with depressive symptoms and loss of the meaning of one's own life.

However, these spiritual experiences could happen as non-pathological problems and, as Prusak puts it, "in most spiritual traditions, mild symptoms of depression are often regarded as signs of spiritual development, whereas its clinical symptoms are sometimes associated with the occurrence and solution of a spiritual crisis" [2].

This is evident in particular in what is often called in the mystical tradition he Dark Night of the Soul. This expression describes a phase in a person's spiritual life, that is associated with a crisis of faith or spiritual concerns about their relationship with God, and that has intrinsic aspects of spiritual growth. As such it is often 
distinguished from clinical depression. It is a painful period of set back, disillusionment, spiritual torment and anguish. Those experiencing the Dark Night of the Soul go through a process of attributing meaning to their experience: they consider it as a process of maturation of their spiritual life, as a natural—not pathological—process in their spiritual development [3].

Such is the case of a middle-aged country preacher who finds himself losing his faith, as depicted in Ingmar Bergman's film "Winter Light" [4], where God is also the reason for a man's grave confusion. When confronted with his congregation, the character is left in a state of despair over the silence of God, revealing the intention of the director in portraying how a man's psyche may be tricked by shallow faith.

These issues are often undervalued at the time of psychiatric assessment but, in that process, there are problems related to a conflict of values, a conflict that may be aggravated by the empiricist/positivist nature of psychiatric theory and by the prioritization of materialist values over values associated with religious accomplishment [5].

Indeed, psychiatrists are also reported to be less religious than the general population [6] which results in a religious gap between them and general public, but as Proudfoot said "to identify an experience in nonreligious terms when the subject himself describes it in religious terms is to misidentify the experience, or to attend to another experience altogether" [7].

In addition, and since mental health professionals are largely disposed to observing psychopathology in people who express suicidal ideation, the assessment is usually made on the assumption that suicidality is driven by psychiatric disorder, supporting a disease-oriented/medical model [8].

\subsection{Suicide and Cultural Values in Portugal}

Traditionally, Portugal is one of the countries with the lowest suicide rates in Europe [9]. The standardized mortality rate (SMR) by suicide is 9.8 per 100,000 inhabitants [10], and although this phenomenon may be under-represented, it is officially lower than SMR by suicide in the European Union.

Geographically within our country, northern regions have lower rates of suicide and this traditional north/south divide has strong cultural roots, with the northern region being more catholic overall.

Our country is also among the most religious countries in Western Europe, with more than a third of Portuguese adults (37\%) showing high levels of religious commitment [11]. It is recognized that these factors may account for the lower suicide rates in the north of our country, although the urban/rural divide is increasing, which may be related to social and economic factors rather than cultural and religious ones [10].

Indeed, religion and spirituality are often seen as means of protection against depression or means of mitigating its symptoms [12] but this phenomenon is very complex and multifactorial. In the case of M., his traditional values and conservative gender role view make him feel useless and want to die. 


\subsection{Values, Suicide Risk and Clinical Decision-Making}

When it comes to suicidal thoughts, patients suffering from serious mental disorder were assumed to lack decision-making capacity. Given the above, we may consider that involuntary hospitalization is likely to be thought as legally and morally justified, since it allows the patient to recover his capacity for self-determination. The Mental Health Act, implemented in Portugal in 1998, permits the psychiatrists to deprive someone with a serious mental disorder of their liberty, since preventing an individual from committing suicide, and eventually treating the psychiatric disorder that is inducing suicidal thoughts, is likely to bring the patient's actions in line with his or her true values. However, this deprivation of individual liberty and autonomy can be experienced as gravely humiliating, even violent [13]; and if we take into account situations where a person is capable of making treatment decisions - uninfluenced by any mental disorder-we enter into the field of rational suicide [14].

A further consideration is that criteria intended to regulate practice leave scope for discretion, and the values and beliefs of staff may become a determining factor for decisions as long as different models of the clinician-patient relationship warrant different interpretations of the legal criteria for involuntary admission [15]. This presents a challenge for mental health professionals, who have their own world view, and raises complex ethical dilemmas relating to compulsory treatment in suicidal individuals, which by its very nature involves a direct conflict of values between the patient and the psychiatrist.

In the case of M., the psychiatric assessment highlighted the emotional suffering experienced by a male individual, with a chronic disease and his own religious and cultural beliefs, who is at risk of committing suicide, even though his symptoms do not meet criteria for a severe mental illness in current psychiatric nosological systems. This complex clinical presentation raises issues about the limitations of defining the heterogeneous construct of mental disorder and the need for a biopsychosocial-spiritual approach. We should respect and support patients' religious beliefs if these help them to cope better and we should also challenge the beliefs that can adversely affect their mental health. When facing psychiatric symptoms with religious content, we might consider incorporating spiritual matters in psychotherapy, so that the therapist could help patients in the process of discovering their own solutions, promoting mutual respect and tolerance for difference.

Although hospitalization seems to be the safest option when dealing with suicidal patients, psychiatrists risk putting their own professional anxieties above the needs of service users. On the other hand, there is no evidence that hospitalization prevents suicide and suicide risk post-hospitalization, immediately following discharge is 100 times greater than average [16]. Trusting therapeutic alliances are fundamental to reducing suicide risk and promoting recovery and wellness, and modern mental health care highlights a shift from paternalism towards a more human rights focused approach, providing care that is respectful of and responsive to individual preferences, needs and values, ensuring that these guide all clinical decisions. 
In the case of M., we suggested that he should start Person-Centred Therapy (Rogerian Therapy), which he accepted, and we encouraged him to meet the hospital chaplain, respecting the value attached to his experience, because he did not feel comfortable in sharing his inner feelings with the priest of his parish.

\subsection{Conclusions}

Spiritual dimension is important in the lives of our patients, since many of their problems revolve around existential and religious issues, for it reflects the underlying cultural and social values.

In the case of M., a conservative and practicing catholic man, there is an inner conflict between constructs such as guilt, sin and rejection, which play an important part in his religious experience, and the loss of the meaning of one's own life, based on the values and standards of his own cultural framework. This intimate struggle resulted in his intention to kill himself, even though this act is absolutely condemned by his religion.

This case illustrates the association between cultural values, spirituality and suicidal ideation, by exploring whether some experiences should be classified as symptoms of a psychiatric disorder or as crises within one's spiritual life.

\subsection{Guide to Further Sources}

Durkheim, EC (1912). The elementary forms of the religious life, a study in religious sociology. London: New York: G. Allen \& Unwin; Macmillan.

James, William, 1842-1910. (1902). The varieties of religious experience: a study in human nature: being the Gifford Lectures on natural religion delivered at Edinburgh in 1901-1902. New York; London: Longmans, Green.

Van Praag HM. The role of religion in suicide prevention In Oxford Textbook of Suicidology and Suicide Prevention (eds Wasserman D, Wasserman C): 7-12. Oxford University Press, 2009.

Koenig HG; Research on religion, spirituality, and mental health: a review. Can J Psychiatry 2009 May; 54(5):283-91.

Telles Correia D. The concept of validity throughout the history of psychiatry. $\mathbf{J}$ Eval Clin Pract (2017) Apr 6.

\section{References}

1. Neeleman J, Halpern D, Leon D, Lewis G. Tolerance of suicide, religion and suicide rates: an ecological and individual study in 19 western countries. Psychol Med. 1997;27:1165-71.

2. Prusak J. Differential diagnosis of "religious or spiritual problem"- possibilities and limitations implied by the V-code 62.89 in DSM-V. Psychiatr Pol. 2016;50(1):175-86.

3. Durà-Vilà G, Dein S. The dark night of the soul: spiritual distress and its psychiatric implications. Ment Health Relig Cult. 2009;12:6,543-59. 
4. Bergman I. Winter light. Sweden: AB Svensk Filmindustri; 1963.

5. Rashed MA. Religious experience and psychiatry: analysis of the conflict and proposal for a way forward. Philos Psychiatr Psychol. 2010;17(3):185-204.

6. Neeleman J, King MB. Psychiatrists' religious attitudes in relation to their clinical practice: a survey of 231 psychiatrists. Acta Psychiatr Scand. 1993;88:420-4.

7. Proudfoot W. Religious experience. Berkeley: University of California Press; 1985. p. 196.

8. Rich KL, Butts JB. Rational suicide: uncertain moral ground. J Adv Nurs. 2004;46:270-83.

9. Gusmão R, Quintão S. Suicide and death resulting from events of undetermined intent register in Portugal. Revisiting "The truth about suicide", 20 years later. Dir Gen Heal J. 2013;1:80-95.

10. Santana P, Costa C, Cardoso G, Loureiro A, Ferrão J. Suicide in Portugal: spatial determinants in a context of economic crisis. Health Place. 2015;35:85-94.

11. Pew Research Center. Being Christian in Western Europe. 29 May 2018.

12. Blazer DG. Spirituality and depression. In: Peteet JR, Lu FG, Narrow WE, editors. Religious and spiritual issues in psychiatric diagnosis. A research agenda for DSM-V. Arlington, VA: American Psychiatric Association; 2011.

13. Sibitz I, et al. Impact of coercive measures on life stories: qualitative study. Br J Psychiatry. 2011;199(3):239-44.

14. Onkay A. Suicide: rationality and responsibility for life. Can J Psychiatry. 2014;59(3):141-7.

15. Feiring E, Ugstad KN. Interpretations of legal criteria for involuntary psychiatric admission: a qualitative analysis. BMC Health Serv Res. 2014;14:500.

16. Chung D, Ryan C, et al. Suicide rates after discharge from psychiatric facilities: a systematic review and meta-analysis. JAMA Psychiatry. 2017;74(7):694-702.

Open Access This chapter is licensed under the terms of the Creative Commons Attribution 4.0 International License (http://creativecommons.org/licenses/by/4.0/), which permits use, sharing, adaptation, distribution and reproduction in any medium or format, as long as you give appropriate credit to the original author(s) and the source, provide a link to the Creative Commons license and indicate if changes were made.

The images or other third party material in this chapter are included in the chapter's Creative Commons license, unless indicated otherwise in a credit line to the material. If material is not included in the chapter's Creative Commons license and your intended use is not permitted by statutory regulation or exceeds the permitted use, you will need to obtain permission directly from the copyright holder.

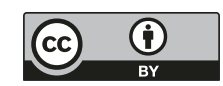

